\title{
IAEA initiatives in the use of noble gas isotopes for improved global groundwater assessment and management

\author{
JODIE MILLER
}

International Atomic Energy Agency

Presenting Author: jodie.miller@iaea.org

Groundwater, the 'invisible' resource, plays a crucial role in sustaining healthy ecosystem functioning and is a critical resource for water and food security from local to global scales. Groundwater is often perceived as an unlimited resource compared to surface water systems, especially as a means for adapting to climate change. Despite its importance, many national water authorities do not have the critical scientific data necessary to fully understand the hydrogeological context of groundwater. This includes the proportion and distribution of renewable vs non-renewable groundwater including the groundwater age distribution, present-day recharge rates, and groundwater-surface water interactions. Among the means available to address these gaps in hydrological information, noble gas isotopes provide largely untapped and powerful tools to gain a better insight into core aspects of groundwater flow and transport in shallow and deep aquifers systems alike. However, a lack of easy access to noble gas analytical facilities, the need to use several isotope tracers, and the requirement to use complex flow models have been critical limiting factors towards the routine use of noble gas isotopes for groundwater investigations. The IAEA has established a noble gas facility enabling member state access to determine ages of young groundwater by the $\mathrm{T}-{ }^{3} \mathrm{He}$ method and deeper old groundwater by the ${ }^{4} \mathrm{He}$ accumulation method. The IAEA also houses a krypton purification system required to prepare samples for long-lived radionuclide krypton-81 analysis by Atom Trap Analysis (ATTA). Noble gas isotopes and other long-lived, non-reactive radionuclides, have expanded the groundwater dating range up to 1 million years B.P., offering the possibility to reassess groundwater flow patterns in several deep sedimentary basins, such as the Nubian aquifer in Africa and the Guarani aquifer in South America. This IAEA presentation discusses the hydrological implications of new noble gas isotope data gathered in the framework of several IAEA-supported collaborative projects. We present recent initiatives to expand and facilitate use of noble gas assays in and by member states, such as advances in field sampling methods and training for data processing and isotope data interpretation. 